\title{
Article \\ Study of Induction Motor Inter-Turn Fault Part II: Online Model-Based Fault Diagnosis Method
}

\author{
Seong-Hwan Im (D) and Bon-Gwan Gu* (D)
}

School of Energy Engineering, Kyungpook National University, Daegu 41566, Korea; imsh9698@naver.com

* Correspondence: bggu@knu.ac.kr

\begin{abstract}
This paper (Part II) is a follow-up paper to our previous work on developing induction motor inter-turn fault (ITF) models (Part I). In this paper, an online ITF diagnosis method of induction motors is proposed by utilizing the negative sequence current as a fault signal based on the fault model of the previous study in part I. The relationships among fault parameters, negative sequence current, and fault copper loss are analyzed with the ITF model. The analyses show that the fault severity index, a function of fault parameters, is directly related to the negative sequence and the copper loss. Therefore, the proposed model-based fault diagnosis method estimates the fault severity index from the negative sequence current and recognizes the ITF. With the estimated fault severity index, the fault copper loss by the ITF, causing thermal degradation, can be calculated. Finally, experiments were performed in various fault conditions to verify the proposed fault diagnosis method.
\end{abstract}

Keywords: inter-turn fault; ITF model; negative sequence; fault parameter; fault diagnosis

check for

updates

Citation: Im, S.-H.; Gu, B.-G. Study of Induction Motor Inter-Turn Fault Part II: Online Model-Based Fault Diagnosis Method. Energies 2022, 15, 977. https://doi.org/10.3390/ en15030977

Academic Editors: Jose A AntoninoDaviu, Toomas Vaimann and Anton Rassõlkin

Received: 27 December 2021

Accepted: 27 January 2022

Published: 28 January 2022

Publisher's Note: MDPI stays neutral with regard to jurisdictional claims in published maps and institutional affiliations.

Copyright: (C) 2022 by the authors. Licensee MDPI, Basel, Switzerland. This article is an open access article distributed under the terms and conditions of the Creative Commons Attribution (CC BY) license (https:// creativecommons.org/licenses/by/ $4.0 /)$.

\section{Introduction}

Induction motors are commonly used as industrial drives due to their cost, reliability, and self-starting advantages. They are composed of many mechanical parts such as stator windings, slots, rotor bars, shafts, and bearings that might occur in machine faults. Bearing and shaft-related failures are gradually decreasing as the manufacturing process improves. However, inter-turn faults (ITF) are still one of the frequent induction motor faults [1,2]. The surface of the stator magnet wire is very thinly coated with insulation material, and it is multiply wrapped in slots to induce high magnetomotive forces. However, the magnet wire insulation layers are not permanent and can be easily lost under various stresses, the socalled "TEAM" stresses as a state in [3-8]. Because ITFs are accompanied by heat generation, it is essential to detect the ITFs incipiently, unlike other machine faults. Otherwise, the ITFs worsen the insulation layer and expand the ITF spot. As a result, the overheated winding by the fault current could cause fatal damage to the motor. In many applications, such as industrial manufacturing, wind power generation, and electric vehicles, in which reliability is the most crucial factor, accurate ITF detection and diagnosis methods are essential.

ITF detection methods have been studied for over 30 years, and, generally, because of the simplicity and low cost, motor current signal analysis (MCSA) has been preferred to diagnose and detect stator ITFs [9-11]. In MCSA, stator ITFs can be detected by the third stator current harmonic and slot harmonics frequency. This method is not sensitive in the low severity fault and cannot identify the stator fault since it is tough to distinguish the fault signal from the noise. Additionally, each machine requires large quantityof pretest datasets to apply the diagnosis methods based on MCSA.

Extended Park's vector approach (EPVA) and the negative sequence current monitoring were studied for stator ITF detection as a more sensitive method [12-15]. In EPVA, the calculated frequency spectrum from Park's vector is analyzed with a fast Fourier transform. Stator faults are diagnosed by the amount of the second and fourth harmonic current increase. Furthermore, the negative sequence current monitoring method uses asymmetry 
components for the stator faults diagnosis $[16,17]$. However, in an industrial motor operating system, most components have inherent asymmetry from winding placements, input grid voltage, phase resistance, etc. Particularly, harmonics and unbalanced components of the input grid voltage make fault diagnosis inaccurate.

Flux-based monitoring methods provide fault diagnosis using hall effect flux sensors or observer coils inside the motor [18-20]. Compared with MCSA methods, flux monitoring methods show high performance and reliability in detecting the stator fault in low-level severity, but additional flux sensor and pretest data are required. Therefore, it can also be a burden in terms of price.

As mentioned above, most of the stator fault detection and diagnosis methods have been performed through signal analysis by imbalance component due to the stator faults, not based on the model. Therefore, to identify accurate fault severity, much pretest data accumulation is necessary for each machine, which is a significant burden in implementing the diagnosis method. Model-based ITF diagnoses have been studied in [21-23] to overcome this problem. The stator faults can be identified with the severity factor from its eccentricity by stator faults using the equation of a 3-D ellipse in phase currents [18-21]. Furthermore, in [22], the negative sequence equivalent circuit model with ITF was derived in the steady-state, and this model was applied to the ITF detection scheme using a feedforward neural network (FFNN) in [23]. In recent papers, fault diagnosis methods were studied using a technique that is a growing variant of the curvilinear component analysis neural network in [24], and the convolutional neural network (CNN) was utilized in the development of intelligent inter-turn fault diagnostic tools in $[25,26]$. However, even if induction motor models were proposed in these studies, these previous models were commonly induced with two-pole motors or a simple equivalent circuit based; thus, it is difficult to establish the fault severity standard and estimate fault parameters.

In this paper, the relationships between the severity of the ITF and additional negative sequence currents and copper loss generated in the fault spot are analyzed with the induction motor ITF model presented in part I [27]. The ITF diagnosis and fault severity estimation method are proposed based on the analyzed negative sequence current deviation. In experiments, the input grid voltage is measured in real time to calculate the negative sequence current in the case of a healthy motor. The calculated negative sequence subtracted from the measured one is used as the fault signal by the ITF. The proposed ITF diagnosis method is verified under various fault conditions, and these show the feasibility of the detection method even in a low-level fault degree.

\section{Negative Sequence Current and Copper Loss Analysis of Induction Motor with ITF}

Figure 1 shows a winding configuration of a 4-pole 36-slot induction motor with an ITF. Here, $a_{1} \sim a_{12}, b_{1} \sim b_{12}$, and $c_{1} \sim c_{12}$ denote the windings of each phase, and $i_{a s}, i_{b s}, i_{c s}$ and $v_{a}, v_{b}, v_{c}$ denote the stator phase currents and voltages, respectively. $R_{f}$ and $i_{f}$ are fault resistance and fault current. When an ITF occurs in $a_{1}$ winding, a part of the stator winding is short-circuited, as shown in Figure 1. The voltage induced at fault closed-circuit generates a high fault current $i_{f}$ due to the low impedance of the fault closed circuit; therefore, the three-phase balanced impedance becomes unbalanced. Particularly, the effect of the fault is reflected in the three-phase current when the motor is operated under the three-phase balanced voltage. Most of the components of unbalanced currents are the negative sequence current, and the worse the fault is, the more negative sequence current invokes; this was verified through simulations and experiments with the proposed fully described and the simplified model in part I [27]. The derived voltage equation of the fully described ITF induction motor model is shown in Equation (1), where $P, n$, $\theta_{r}, R_{s}, R_{r}, v_{d q s}^{s}, i_{d q s^{s}}^{s}$ and $i_{d q r 1 \sim P}^{s}$ denote a pole number, number of windings per phase, the rotor position angle, stator resistance, rotor resistance, stator $\mathrm{d}$, q-axis voltage, stator $\mathrm{d}, \mathrm{q}$-axis current in the stator stationary reference frame, and rotor $\mathrm{d}, \mathrm{q}$-axis current in the rotor stationary reference frame, respectively. $L_{m}, L_{l r}, L_{s m}$, and $L_{s l}$ are stator magnetizing inductance, rotor leakage inductance, stator one slot winding magnetizing, and stator 
one slot leakage inductance, respectively. $x, \gamma_{s}$, and $\alpha_{k}$ are healthy turn ratio, stator interwinding coupling factor, Fourier coefficients of the winding coupling factors between the rotor winding and the fault winding, respectively. With (1), the transient and steady-state response can be simulated.

$$
v_{\text {ITF model }}=\left[\begin{array}{cc}
\mathbf{R}_{\mathrm{dqs}} & \mathbf{0}_{[3 \times 2 \mathrm{P}]} \\
\mathbf{0}_{[2 \mathrm{P} \times 3]} & \frac{\mathrm{R}_{\mathrm{r}}}{\mathrm{P}} \mathbf{I}_{[2 \mathrm{P} \times 2 \mathrm{P}]}
\end{array}\right] i_{\text {ITF model }}+\frac{d}{d t}\left[\begin{array}{cc}
\mathbf{L}_{\mathbf{s}} & \mathbf{L}_{\mathbf{s r}[3 \times 2 \mathrm{P}]} \\
\mathbf{L}_{\mathbf{r s}[2 \mathrm{P} \times 3]} & L_{\mathbf{r}} \mathbf{I}_{[2 \mathrm{P} \times 2 \mathrm{P}]}
\end{array}\right] i_{\text {ITF model }}
$$

where $v_{\text {ITFmodel }}=\left[\begin{array}{llll}v_{d s}^{s} & v_{q s}^{s} & 0 & \mathbf{0}_{[1 \times 2 \mathrm{P}]}\end{array}\right]^{T}, \boldsymbol{i}_{\text {ITF model }}=\left[\begin{array}{lllllllll}i_{d s}^{s} & i_{q s}^{s} & i_{f} & i_{d r 1}^{s} & \cdots & i_{d r P}^{s} & i_{q r 1}^{s} & \cdots & i_{q r P}^{s}\end{array}\right]^{T}$, $\mathbf{I}_{[2 \mathrm{P} \times 2 \mathrm{P}]}$ : identity matrix of size $2 \mathrm{P}, \mathbf{0}$ : null matrix, $\mathbf{R}_{\mathbf{d q s}}=\left[\begin{array}{ccc}R_{d s} & 0 & R_{d s f} \\ 0 & R_{q s} & 0 \\ R_{f d s} & 0 & R_{f f}\end{array}\right], \mathbf{L}_{\mathbf{s}}=\left[\begin{array}{ccc}L_{d s} & 0 & L_{d s f} \\ 0 & L_{q s} & 0 \\ L_{f d s} & 0 & L_{f f}\end{array}\right]$,

$$
\begin{aligned}
& \mathbf{L}_{\mathbf{s r}[3 \times 2 P]}=\left[\begin{array}{cccccc}
L_{d s d r 1} & \cdots & L_{d s d r P} & L_{d s q r 1} & \cdots & L_{d s q r P} \\
L_{q s d r 1} & \cdots & L_{q s d r P} & L_{q s q r 1} & \cdots & L_{q s q r P} \\
L_{f d r 1} & \cdots & L_{f d r P} & L_{f q r 1} & \cdots & L_{f q r P}
\end{array}\right], \mathbf{L}_{\mathbf{r s}[2 P \times 3]}=\left[\begin{array}{cccccc}
L_{d r 1 d s} & \cdots & L_{d r P d s} & L_{q r 1 d s} & \cdots & L_{q r P d s} \\
L_{d r 1 q s} & \cdots & L_{d r P q s} & L_{q r 1 q s} & \cdots & L_{q r P q s} \\
L_{d r 1 f} & \cdots & L_{d r P f} & L_{q r 1 f} & \cdots & L_{q r P f}
\end{array}\right]^{T}, \\
& R_{d s}=R_{s}-\frac{2}{3} \frac{(1-x)}{n} R_{s}, R_{q s}=R_{s}, R_{f f}=\frac{2}{3} \frac{(1-x)}{n} R_{s}+\frac{2}{3} R_{f}, R_{d s f}=\frac{2}{3} \frac{(1-x)}{n} R_{s}, R_{f d s}=-\frac{2}{3} R_{f} \text {, } \\
& L_{d s}=\frac{1}{3}\left(2 L_{s a a}+L_{m} \frac{n-1+x}{n}+\frac{3}{2} L_{m}+L_{l s}\right), L_{q s}=\frac{3}{2} L_{m}+L_{l s}, L_{f d s}=\frac{1}{3}\left(2 L_{s f a}+\frac{1-x}{n} L_{m}\right), \\
& L_{d s f}=\frac{1}{3}\left(2 L_{s a f}+\frac{1-x}{n} L_{m}\right), L_{f f}=\frac{2}{3} L_{s f f}, \\
& L_{s f a}=x(1-x)\left(L_{s m}+L_{s l}\right)+\frac{1}{2} \frac{\gamma_{s}}{n}(1-x) L_{s m}, L_{s a a}=\left(n-1+x^{2}\right)\left(L_{s m}+L_{s l}\right)+\gamma_{s} L_{s m} \frac{n-1+x}{n}+L_{s f a} \\
& L_{s f f}=(1-x)^{2}\left(L_{s m}+L_{s l}\right), L_{s a f}=x(1-x)\left(L_{s m}+L_{s l}\right)+\frac{1}{2} \frac{\gamma_{s}}{n}(1-x) L_{s m}+L_{s f f}, L_{\mathrm{r}}=\frac{3 L_{m} / 2+L_{l r}}{P}, \\
& L_{f d r(i)}=\frac{3 L_{m}}{P n}(1-x) \sum_{k=1}^{\infty} \alpha_{k} \cos k\left(\theta_{r}+(i-1) \frac{2 \pi}{P}\right)=L_{d r(i) f}, \\
& L_{f q r(i)}=\frac{3 L_{m}}{P n}(1-x) \sum_{k=1}^{\infty} \alpha_{k} \cos k\left(\theta_{r}+\left(i-\frac{1}{2}\right) \frac{2 \pi}{P}\right)=L_{q r(i) f}, \\
& L_{d s d r(i)}=L_{q s q r(i)}=L_{q r(i) q s}=(-1)^{i-1} \frac{3}{2} \frac{L_{m}}{P} \cos \frac{\theta_{r} P}{2}, L_{d s q r(i)}=-L_{q s d r(i)}=-L_{d r(i) q s}=(-1)^{i \frac{3}{2}} \frac{L_{m}}{P} \sin \frac{\theta_{r} P}{2} \text {, } \\
& L_{d r(i) d s}=L_{d s d r(i)}-L_{d r(i) f}, L_{q r(i) d s}=L_{d s q r(i)}-L_{q r(i) f} .
\end{aligned}
$$

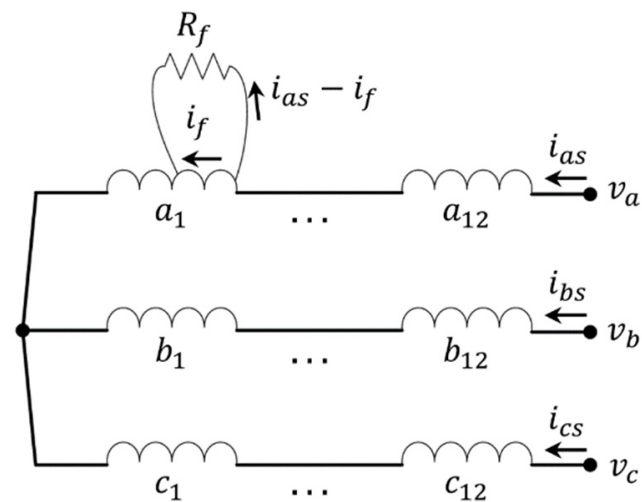

Figure 1. 4-pole 36-slot Induction motor series connected winding configuration with an ITF.

Figure 2 shows a circuit of $a_{1}$ winding with an ITF. Here, $\Lambda_{\mathbf{a} 1 \mathrm{~m}}$ denotes the coupled $a_{1}$ winding flux linkage from other stator windings $\left(a_{2} \sim a_{12}, b_{1} \sim b_{12}\right.$, and $\left.c_{1} \sim c_{12}\right)$ and the rotor windings $(d q 1 \sim d q P) ; \mathbf{i}_{\text {as }}$ is $a$-phase current in the complex domain. Analyzing under 
the steady-state condition, they are assumed as constant complex values. Considering the faulty $a_{1}$ winding circuit, the steady-state fault current $\mathbf{i}_{\mathbf{f}}$ can be derived as (2).

$$
\mathbf{i}_{\mathbf{f}}\left(x, R_{f}\right)=\frac{\frac{R_{f} \mathbf{i}_{\mathbf{a s}}}{(1-x)^{2}}-\frac{j \omega \boldsymbol{\Lambda}_{\mathbf{a} 1 \mathbf{m}}}{1-x}-\frac{j \omega x\left(L_{s m}+L_{s l}\right) \mathbf{i}_{\mathbf{a s}}}{1-x}}{\frac{R_{s}}{n(1-x)}+\frac{R_{f}}{(1-x)^{2}}+j \omega\left(L_{s m}+L_{s l}\right)}
$$

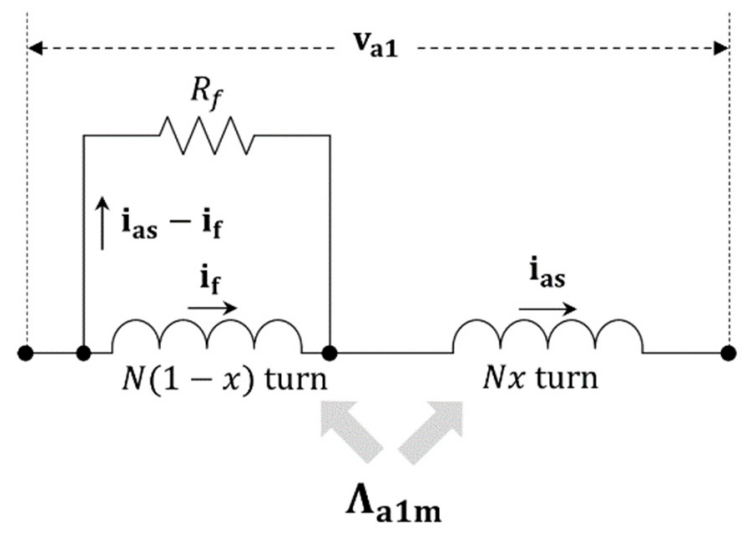

Figure 2. Circuit of $a_{1}$ winding with the ITF.

From (2), the fault current $\mathbf{i}_{\mathbf{f}}$ is defined by fault parameters $x$ and $R_{f}$. With (2), the $a_{1}$ winding flux linkage $\Lambda_{\mathrm{a} 1}$ with the ITF can be expressed as (3).

$$
\begin{gathered}
\boldsymbol{\Lambda}_{\mathbf{a} 1}=\boldsymbol{\Lambda}_{\mathbf{a} 1 \mathbf{m}}+\left(L_{s m}+L_{l s}\right)\left((1-x) \mathbf{i}_{\mathbf{f}}+x \mathbf{i}_{\mathbf{a s}}\right) \\
=\boldsymbol{\Lambda}_{\mathbf{a} 1 \mathbf{m}}+\left(L_{s m}+L_{l s}\right) \mathbf{i}_{\mathbf{a s}}-\left(L_{s m}+L_{l s}\right)\left[\frac{\frac{R_{s}}{n} \mathbf{i}_{\mathbf{a s}}+j \omega \boldsymbol{\Lambda}_{\mathbf{a} 1 \mathbf{m}}+j \omega\left(L_{s m}+L_{s l}\right) \mathbf{i}_{\mathbf{a s}}}{f_{x R}+j \omega\left(L_{s m}+L_{s l}\right)}\right] \\
\text { where } f_{x R}\left(x, R_{f}\right)=\frac{R_{s}}{n(1-x)}+\frac{R_{f}}{(1-x)^{2}}
\end{gathered}
$$

The first and the second term on the right-hand side of (3) represent the healthy $a_{1}$ winding flux linkage without any ITF. Hence, only the third term describes the distorted $a_{1}$ winding flux linkage by the ITF and invokes the unbalanced three-phase current and the distorted stator and rotor flux linkage. This is the only cause of all flux distortion and fault signal generation. Note that it is a function not of specific fault parameters, i.e., $x$ (healthy turn ratio) and $R_{f}$ (fault resistance), but of $f_{x R}\left(x, R_{f}\right)$, which is a function of them. $f_{x R}\left(x, R_{f}\right)$ was first introduced as an ITF severity index of a permanent magnet synchronous motor in [28] and it was proven that a given $f_{x R}$ can represent the ITF influence without both specific $x$ and $R_{f}$ information.

In the same manner as a derivation of (3), the coupled flux linkage $\Lambda_{\text {ma1 }}$ from the $a_{1}$ winding to other windings can be obtained using the function of $f_{x R}\left(x, R_{f}\right)$ as follows:

$$
\boldsymbol{\Lambda}_{\mathbf{m a} 1}=x L_{s m} \mathbf{i}_{\mathbf{a s}}+(1-x) L_{s m} \mathbf{i}_{\mathbf{f}}=L_{s m} \frac{f_{x R} \mathbf{i}_{\mathbf{a s}}-\frac{R_{s}}{n} \mathbf{i}_{\mathbf{a s}}-j \omega \boldsymbol{\Lambda}_{\mathbf{a} 1 \mathbf{m}}}{f_{x R}+j \omega\left(L_{s m}+L_{s l}\right)}
$$

$\Lambda_{\text {mal }}$ is the total flux linkage which can be coupled with other windings. The specific coupled flux linkage should consider the turn ratio and the magnetic coupling ratio. From (4), the faulty $a_{1}$ winding affects other windings as a form of $\Lambda_{\mathrm{ma}}$, and it is a function of the fault severity index $f_{x R}\left(x, R_{f}\right)$, not of respective fault parameters. This implies that the distortion of the coupled flux linkage from the faulty winding is resolved by $f_{x R}$. Hence, the ITF effect on other stator and rotor windings is also defined by it, not the respective 
fault parameters. From (2), $\mathbf{i}_{\mathrm{f}}$ is resolved by both $x$ and $R_{f}$. However, the distorted coupled flux linkages are identical for the identical $f_{x R}$, regardless of $x$ and $R_{f}$.

With (2) and Figure 2, the voltage distortion induced in the faulty $a_{1}$ winding is derived as Equation (5).

$$
\mathbf{v}_{\mathbf{a} 1}(x=1)-\mathbf{v}_{\mathbf{a} 1}(x)=\left(j \omega_{e}\left(L_{s m}+L_{s l}\right)+\frac{R_{s}}{n}\right)\left(\frac{j \omega\left(L_{s m}+L_{s l}\right) \mathbf{i}_{\mathbf{a s}}+j \omega \boldsymbol{\Lambda}_{\mathbf{a} 1 \mathbf{m}}+\frac{R_{s}}{n} \mathbf{i}_{\mathbf{a s}}}{f_{x R}+j \omega\left(L_{s m}+L_{s l}\right)}\right)
$$

Here, $x$, healthy turn ratio of $a_{1}$ winding satisfies $0 \leq x \leq 1$, and $x=0$ and $x=1$ represent the full and no ITF. $\mathbf{v}_{\mathbf{a} 1}(x)$ and $\mathbf{v}_{\mathbf{a} 1}(x=1)$ denote the $a_{1}$ winding voltage when the motor has an ITF and no ITF, respectively. From (5), it can also be seen that the distorted phase voltage is determined by $f_{x R}\left(x, R_{f}\right)$, not by respective values of $x$ and $R_{f}$. In (5), the distorted voltage by the ITF with a given phase current $\mathbf{i}_{\text {as }}$ is presented. Conversely, if the motor with the ITF is operated under the three-phase balanced input voltage, the unbalanced component by the ITF must be reflected in the three-phase currents. Since the dynamic equation of the motor system is identical, these unbalanced currents are also determined by $f_{x R}$. Hence, $\mathbf{i}_{\mathbf{a}}(x=1)-\mathbf{i}_{\mathbf{a}}(x)$ will be a function of $f_{x R}$.

Figure 3 shows a plot of calculated negative sequence current $\mathbf{i}_{\mathbf{d q s}}^{-\mathbf{e}}$ with fully described model (1) vs. $f_{x R}$ with varying $R_{f}$ and fixed $x$ (3-turns and 5-turns fault), respectively. The motor used in the calculation is a 4-pole 36 slot motor with 36 windings shown in Figure 1, and a rated voltage $380 \mathrm{Vrms}$ line-lineand $60 \mathrm{~Hz}$, was applied under no load condition. In part I [27], it was shown that the load condition has no dependency on the stator negative sequence current $\mathbf{i}_{\mathbf{d q s}}^{-\mathbf{e}}$ by ITF. The motor parameters are listed in Table 1. The solid red line and black dot-dashed line denote under 3-turns and 5-turns fault, respectively. The results show that the same negative sequence current magnitude occurs under the same $f_{x R}$, regardless of each fault parameter, $x$ and $R_{f}$. It is also observed that the magnitude of the generated negative sequence current increases as $f_{x R}$ decreases. Therefore, the fault severity index $f_{x R}$ can be estimated using model (1) and obtained negative sequence current component.

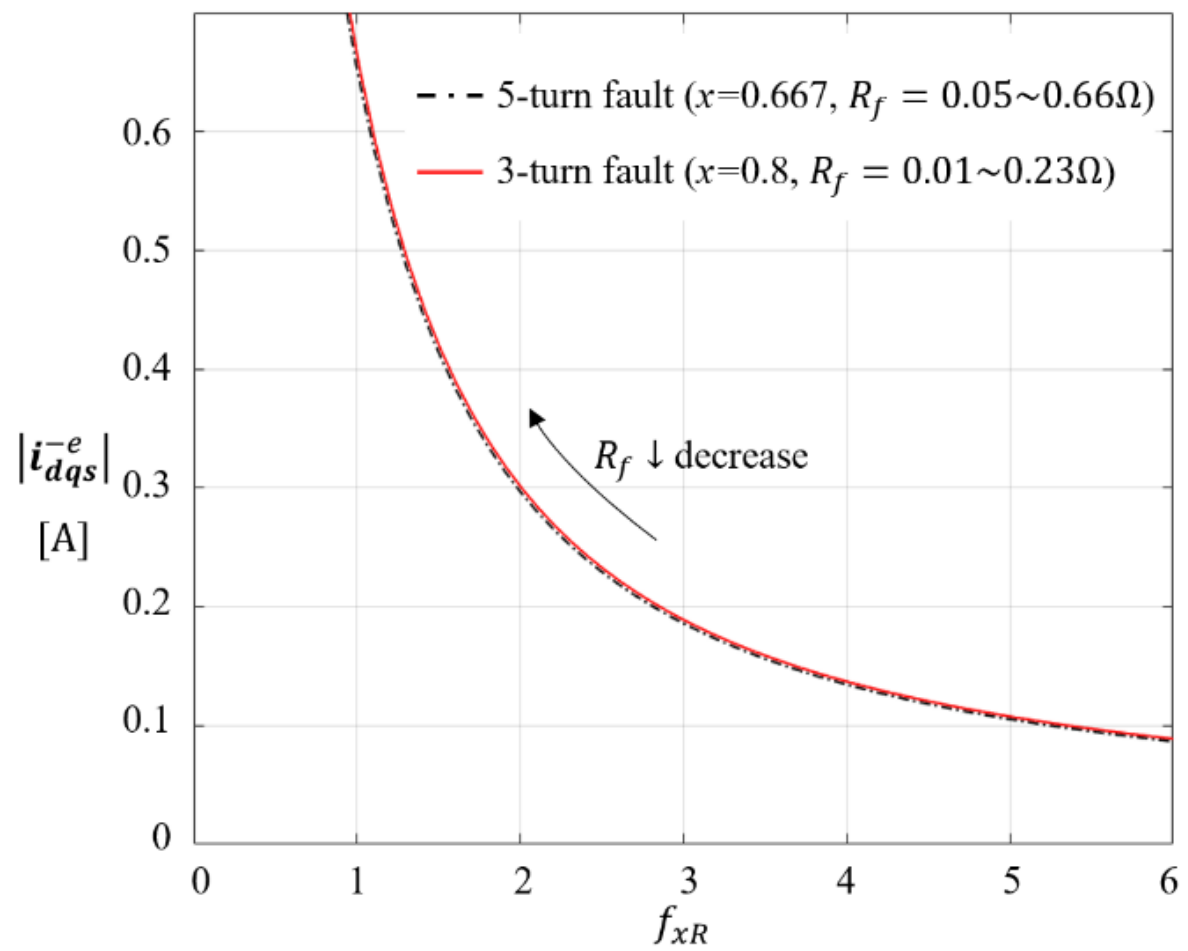

Figure 3. Calculated negative sequence current vs. $f_{x R}$ with 3-turns and 5-turns faults. 
Table 1. Motor Specifications.

$\left.\begin{array}{ccc}\hline \text { Items } & \text { Values } & \text { Units } \\ \hline \text { Pole number } & 4 & \\ \text { Rated output power } & 3.7 & {[\mathrm{~kW}]} \\ \text { Rated phase current } & 11.9 & {\left[I_{\text {peak }}\right]} \\ \text { Rated phase voltage } & 220 & {\left[V_{r m s}\right]} \\ \text { Rated speed } & 1740 & {[\mathrm{rpm}]} \\ \text { Self-magnetizing inductance } L_{m} & 0.123 & {[\mathrm{H}]} \\ \text { Stator leakage inductance } L_{l s} & 0.0085 & {[\mathrm{H}]} \\ \text { Rotor leakage inductance } L_{l r} & 0.0085 & {[\mathrm{H}]} \\ \text { Stator phase resistance } R_{s} & 1.06 & {[\Omega]} \\ \text { Rotor phase resistance } R_{r} & 0.93 & {[\Omega]} \\ \text { Winding turns per slot } & 15 & \\ \text { Stator inter-winding coupling factor } \gamma_{s} & 36.295 & \\ \text { Rotor-fault coupling factor }\left\{\alpha_{1}, \alpha_{2}, \alpha_{3},\right. \\ \alpha_{4}, \alpha_{5}, \alpha_{6}, \\ \alpha_{7}, \alpha_{8}\end{array}\right\} \quad\left\{\begin{array}{cc} \\ \text { Fault resistance } R_{f} & 0.180,-0.082,0.000, \\ \text { Healthy turn ratio } x & 0.129,0.088 \\ \hline\end{array}\right.$

However, it is hard to be sure that the same severity of fault occurs in the constant $f_{x R}$ without copper loss analysis because the generated negative sequence current is constant. The large fault current induces additional copper loss, which gives heat damage to the local neighboring winding. If the additional copper loss by the ITF is defined by $f_{x R}$ not the respective fault parameters, the fault effects on the neighboring winding could be calculated using estimated $f_{x R}$. Therefore, it is essential to analyze the copper loss by the ITF. Under the constant $f_{x R}$, since the same positive and negative current is generated, the copper losses, occurring in the healthy windings $\left(a_{1 h}, a_{2}, a_{3}, \ldots a_{12}\right)$, by the ITF is constant.

$$
\begin{gathered}
P_{\text {ITF, total }}=\frac{1}{2} \frac{R_{s}}{n}(1-x)\left(\mathbf{i}_{\mathbf{f}} \mathbf{i}_{\mathbf{f}}^{*}-\mathbf{i}_{\mathbf{a s}} \mathbf{i}_{\mathbf{a s}}^{*}\right)+\frac{1}{2} R_{f}\left(\mathbf{i}_{\mathbf{a s}}-\mathbf{i}_{\mathbf{f}}\right)\left(\mathbf{i}_{\mathbf{a s}}-\mathbf{i}_{\mathbf{f}}\right)^{*} \\
=\frac{\omega^{2} f_{x R}}{2} \frac{\left(\left(L_{s m}+L_{s l}\right) \mathbf{i}_{\mathbf{a s}}+\boldsymbol{\Lambda}_{\mathbf{a} 1 \mathbf{m}}\right)\left(\left(L_{s m}+L_{s l}\right) \mathbf{i}_{\mathbf{a s}}^{*}+\boldsymbol{\Lambda}_{\mathbf{a} 1 \mathbf{m}}^{*}\right)-\frac{R_{s}^{2}}{n^{2}} \mathbf{i}_{\mathbf{a s}} \mathbf{i}_{\mathbf{a s}}^{*}}{f_{x R}^{2}+\omega^{2}\left(L_{s m}+L_{s l}\right)^{2}} \\
-\frac{R_{s} \omega^{2}\left(L_{s m}+L_{s l}\right)}{2 n} \frac{\left(2\left(L_{s m}+L_{s l}\right) \mathbf{i}_{\mathbf{a s}} \mathbf{i}_{\mathbf{a s}}^{*}+\mathbf{i}_{\mathbf{a s}}^{*} \boldsymbol{\Lambda}_{\mathbf{a} 1 \mathbf{m}}+\mathbf{i}_{\mathbf{a s}} \boldsymbol{\Lambda}_{\mathbf{a} 1 \mathbf{m}}^{*}\right)}{f_{x R}^{2}+\omega^{2}\left(L_{s m}+L_{s l}\right)^{2}}
\end{gathered}
$$

The entire copper loss generated in the ITF circuit can be divided into the main stator path with $i_{f}$ and the shorted circuit with $i_{a}-i_{f}$, and derived as (6) using the calculated fault current $\mathbf{i}_{\mathbf{f}}$. As (3)-(5), the copper loss generated in the ITF circuit $P_{I T F, t o t a l}$ is also defined by $f_{x R}$. Hence, after estimating the fault severity index $f_{x R}$, the heat damage by the ITF could be represented.

Theoretically, the minimum value of $f_{x R}$ is at least $R_{a 1}$, when $R_{f}=0$ and $x=0$. In the case of the induction motor under study, when the fault turn numbers are 15-turns $(x=0)$ and 1-turn $(x=0.933)$, the minimum $f_{x R}$ become 0.09 and 1.35 at $R_{f}=0$, respectively. Figure 4 shows the calculated copper loss of the faulty winding with the fully described induction motor ITF model (1). In Figure 4a, the solid lines represent the copper losses $P_{I T F, R_{s}}$ generated at the main path of faulty winding with the resistance $\frac{R_{s}}{n}(1-x)$ when the healthy turn ratio $x$ is 0.0 (15-turns fault), 0.8 (3-turns fault), and 0.933(1-turn fault). The dashed lines denote the copper losses $P_{I T F, R_{f}}$ generated at the shorted path of faulty winding with the fault resistance $R_{f}$. As shown in Figure $4 \mathrm{a}, P_{I T F, R_{s}}$ and $P_{I T F, R_{f}}$ have different values depending on fault parameters $x$ and $R_{f}$. The lower the number of fault turns, the smaller the range of copper losses that can occur. A 1-turn fault has a minimum range of copper losses, as shown in the blue line of Figure 4a. 


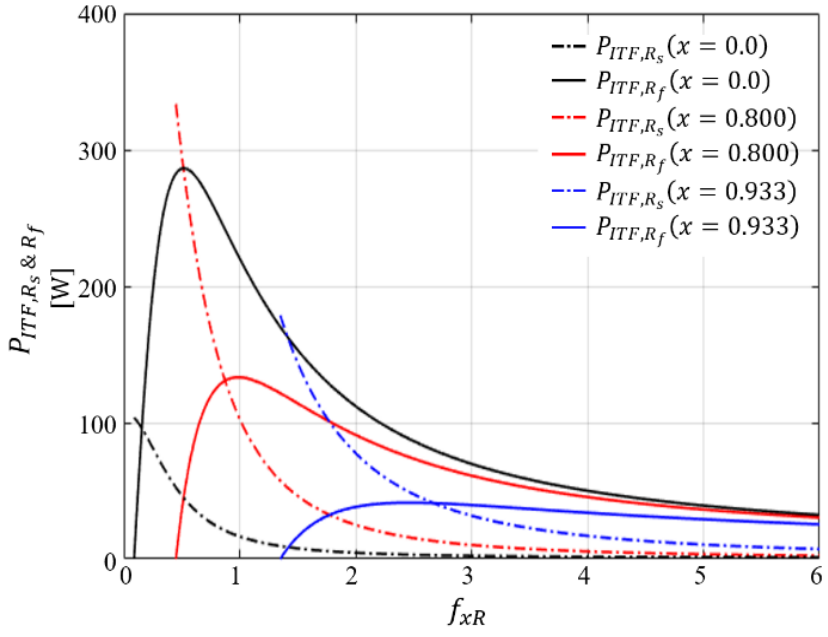

(a)

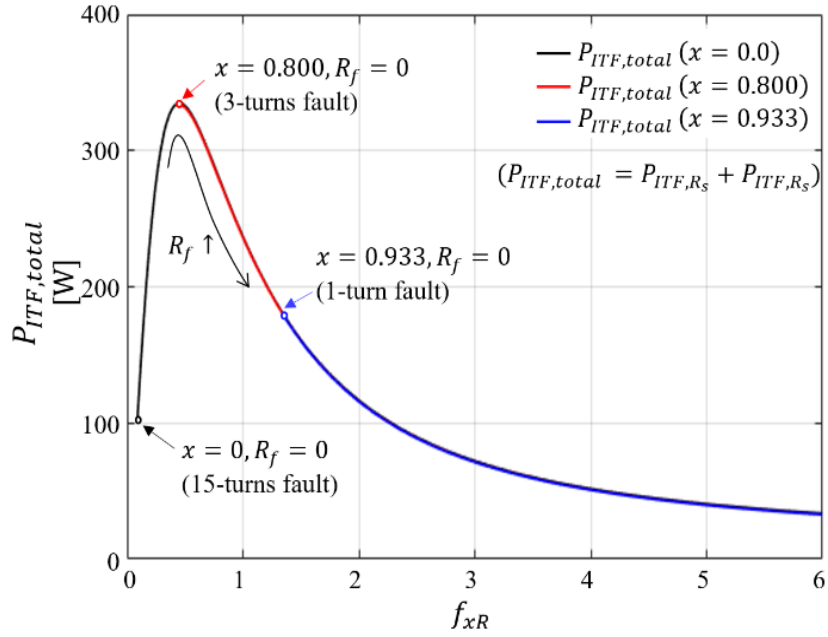

(b)

Figure 4. Calculated power losses, (a) $P_{I T F, R_{s}}$ and $P_{I T F, R_{f}}$, and (b) $P_{I T F, \text { total }}$ with $x=0.0,0.8$ and 0.933 .

Figure $4 \mathrm{~b}$ shows the entire copper loss $P_{I T F, \text { total }}$, which is the sum of $P_{I T F, R_{s}}$ and $P_{I T F, R_{f}}$ when $x=0.0,0.8$, and 0.933 . These are almost identical regardless of fault turn number under constant $f_{x R}$. However, because $f_{x R}$ has its minimum value depending on the healthy turn ratio $x$, the copper loss ranges also vary. $P_{I T F, \text { total }}$ has a maximum value at $f_{x R}=\omega L_{a 1}$. From Figure 4 , the degree of ITF can be determined by $f_{x R}$, though the copper loss ranges differ depending on $x$. As a result, it is possible to estimate the copper loss generated in the ITF circuit when $f_{x R}$ is estimated through the negative sequence current.

\section{Fault Diagnosis Method and Fault Severity Index Estimation}

The ITF diagnosis is essential to prevent rapid expansion of fault spots and unnecessary local temperature rise, resulting in a fire hazard. As shown in Figures 3 and 4, when an ITF occurs, the magnitude of the negative sequence current and the copper loss is determined by the fault severity index $f_{x R}$, not the specific fault parameters $x$ and $R_{f}$. Furthermore, since the generated negative sequence current by the ITF increases as $f_{x R}$ decreases, this is used as a fault signal in the proposed diagnosis method. To calculate the additional power loss in the faulty winding, $f_{x R}$ is estimated based on the relationship between $i_{d q s}^{-e}$ and $f_{x R}$ in Figure 3.

Figure 5 shows a block diagram of the proposed fault diagnosis method. The applied three-phase voltages $v_{a b c}$ to the induction motor and three-phase currents $i_{a b c}$ are measured. Three-phase currents $i_{a b c}$ are converted into a negative sequence current $i_{d q s}^{-e}$ with phase voltage $v_{a b c}$, electrical angle $\theta_{\mathrm{e}}$, and low pass filter. Even without the ITF, the negative sequence current may be caused by various factors. Particularly, unbalanced input threephase voltage from the grid plays a great role when it comes to the unbalanced current generation. Although the negative sequence voltage effect of the grid is much insignificant compared with the ITF, it must be considered for accurate fault diagnosis. To establish precise criteria of the ITF by excluding the grid negative sequence voltage effect, the healthy motor current $(x=1)$ is calculated in real time using the healthy motor negative sequence admittance $\mathbf{Y}_{\mathbf{n}}$ in [29], with measured three-phase voltage $v_{a b c}$ as an input voltage, and these are converted into the healthy negative sequence current $i_{d q s, h}^{-e}$, which is a base value without the ITF. 


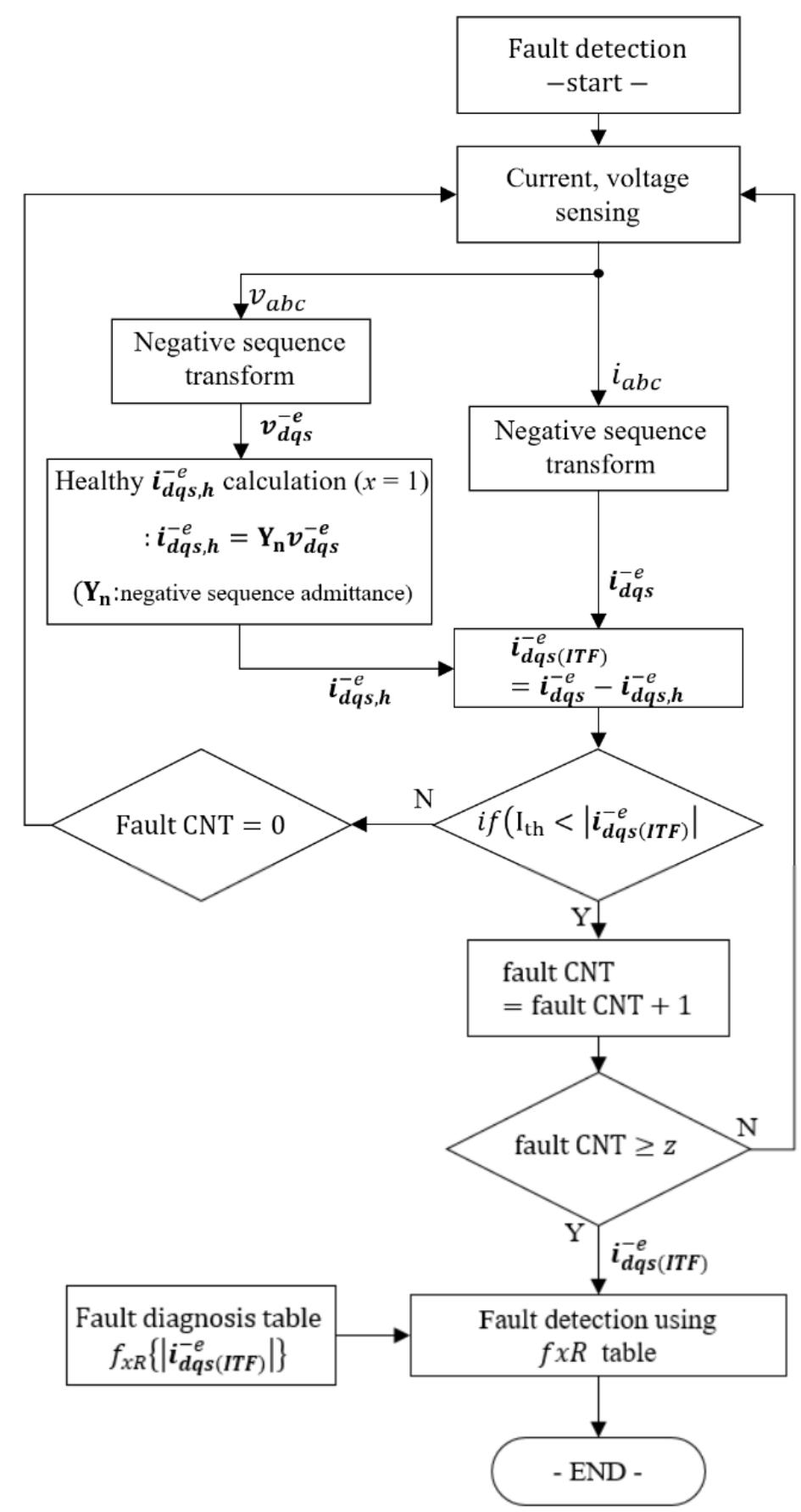

Figure 5. Block diagram of proposed ITF diagnosis and $f_{x R}$ estimation method.

To diagnose the ITF, $i_{d q s}^{-e}$ is compared with the healthy negative sequence current $i_{d q s, h}^{-e}$ in real time. The negative sequence current that occurs additionally by the ITF can be expressed as $i_{d q s(I T F)}^{-e}=i_{d q s}^{-e}-i_{d q s, h}^{-e}$. In the method, $\mathrm{I}_{\text {th }}$ denotes the threshold level of the negative sequence current to detect an ITF. $\mathrm{I}_{\mathrm{th}}$ is set to the maximum value of $i_{d q s(\text { ITF })}^{-e}$ in the absence of ITFs. When $\left|i_{d q s(I T F)}^{-e}\right|$ is greater than the threshold current $I_{\text {th }}$, the fault counter increases. However, if it is confirmed that the occurred negative sequence currents were caused by a temporary error rather than an ITF, the fault counter is initialized to zero. In this way, it is possible to ignore the negative sequence current caused by the spark current or measurement error. Finally, when the fault count is over a certain value $z$, it is judged as the ITF, and at this time, the fault degree $f_{x R}$ is estimated by $f_{x R}\left\{\left|i_{d q s(T T F)}^{-e}\right|\right\}$ of Figure 3. 


\section{Experimental Results}

Figure 6 shows the configuration of the experimental setup for the ITF diagnosis, $f_{x R}$ estimation, and fault power loss estimation. The negative sequence current $i_{d q s}^{-e}$ is obtained from transforming the three-phase currents $i_{a b c}$ into the negative rotating synchronous reference frame and removing the alternating components by applying the low pass filter. $i_{d q s}^{+e}$ denotes the positive sequence current. $\theta_{\mathrm{e}}$ is obtained from the three-phase voltage $v_{a b c}$ with PLL.

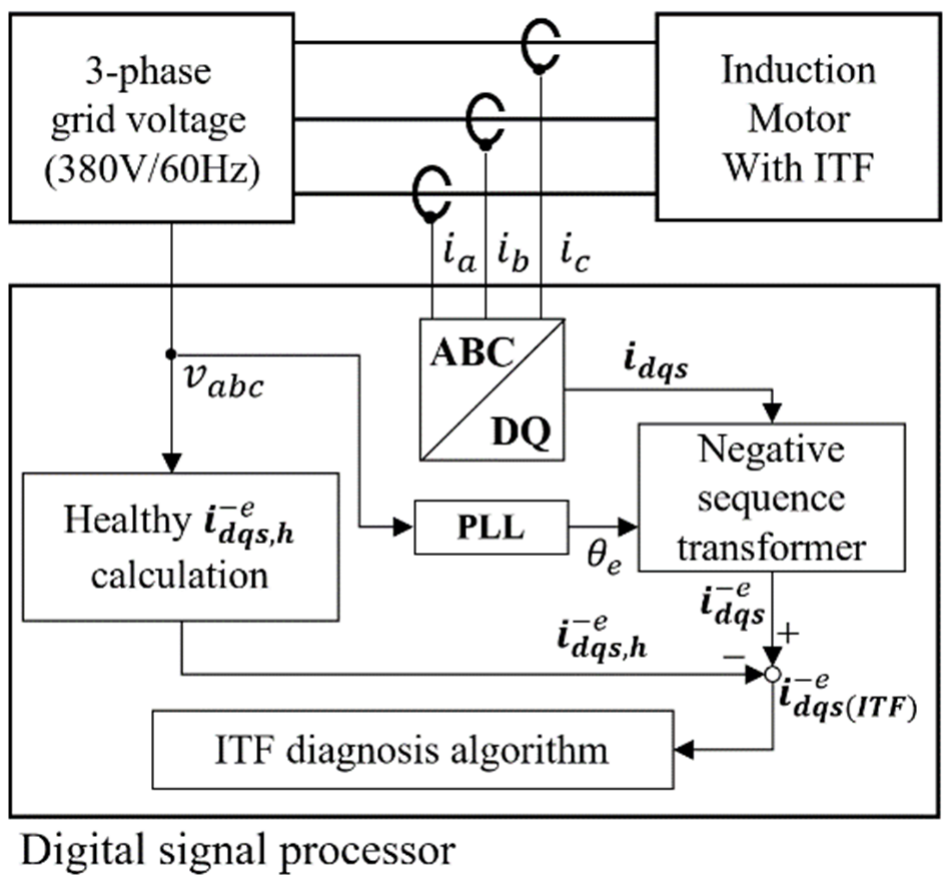

Figure 6. Configuration of the experiment setup.

Some of the stator windings were pulled out through the back of the motor. These windings were connected to an external switch with a fault resistor, and the switch was turned on when a fault condition was given. The fault turn number can be set to 3- or 5-turns; the noninductive resistors $0.065,0.079,0.112,0.186,0.233,0.327$, and $0.544 \Omega$ are used as fault resistors in the experiments. The fault signals are barely related to the load condition, so all experiments were conducted under no load condition.

\subsection{Verification of Negative Sequence Current Generation and Copper Loss Caused by ITF}

Figure 7 shows plots of fault current and negative sequence current under various fault conditions when $f_{x R}$ are 2.08 (Figure 7a, $x=0.8, R_{f}=0.065 \Omega$ ), 1.94 (Figure $7 \mathrm{~b}$, $x=0.667, R_{f}=0.186 \Omega$ ), 5.10 (Figure $7 \mathrm{c}, x=0.8, R_{f}=0.186 \Omega$ ), and 5.16 (Figure $7 \mathrm{~d}$, $\left.x=0.667, R_{f}=0.544 \Omega\right)$, respectively. The three-phase voltage (380 Vrms, line-line, $60 \mathrm{~Hz}$ ) was applied to the motor, and the external switch was turned on at $1.0 \mathrm{~s}$ to introduce the ITF. In Figure 7, before $1.0 \mathrm{~s},\left|i_{d q s}^{-e}\right|$ have a DC 150 200 mA offset without ITF. This comes from the negative sequence current from the negative sequence voltage of the grid. In Figure $7 \mathrm{a}, \mathrm{b}$, the magnitudes of the negative sequence current $\left|i_{d q s}^{-e}\right|$ increase after $1.0 \mathrm{~s}$ with the ITF. However, in Figure 7c,d, they contrarily decrease with the ITF. Since Figure 7a,b have been conducted with less $f_{x R}$ and more severe ITF than Figure $7 \mathrm{c}, \mathrm{d}$, the invoked negative sequence current magnitude is larger, and so it is larger than the offset value. However, in the case of light ITF, the invoked negative sequence current is buried in the one by the nonideal grid if only its magnitude is observed as a fault signal. 


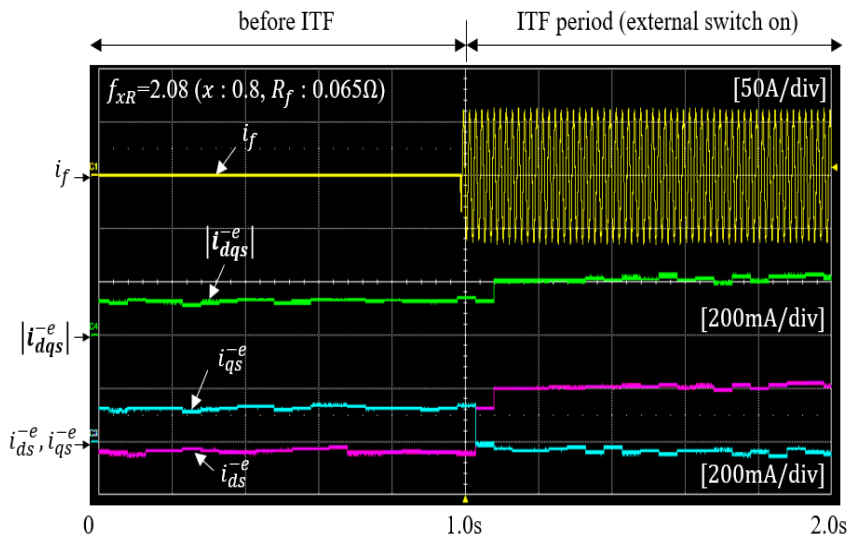

(a)

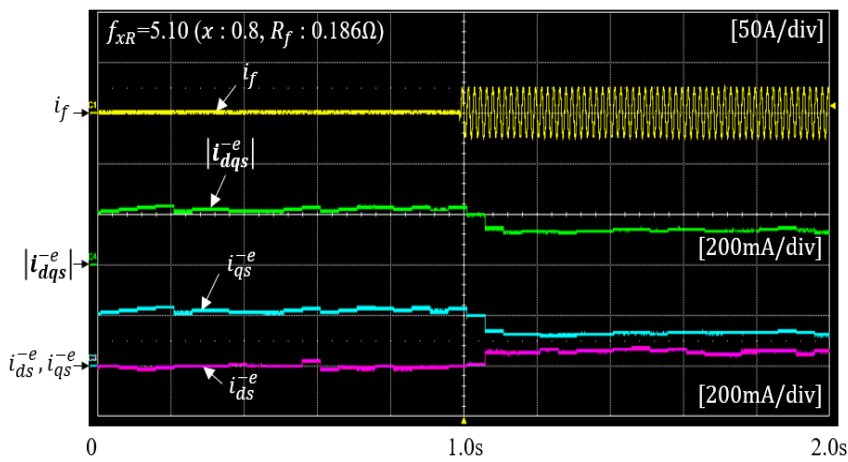

(c)

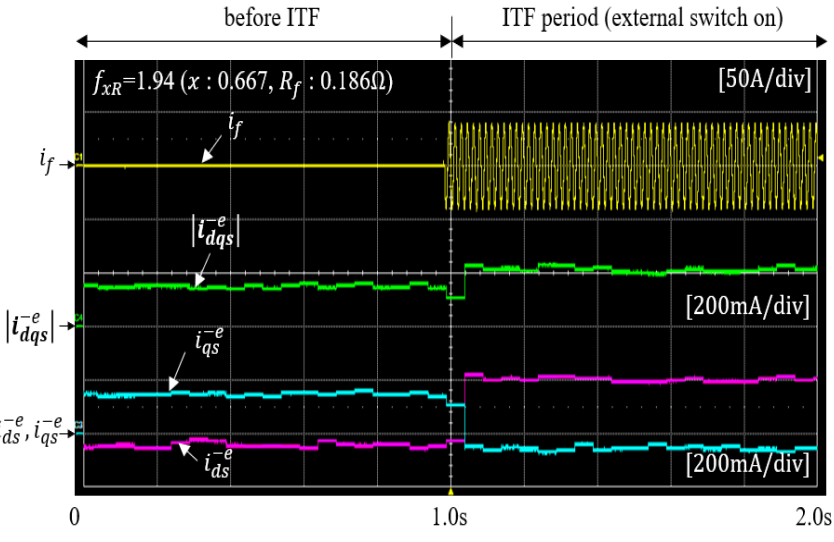

(b)

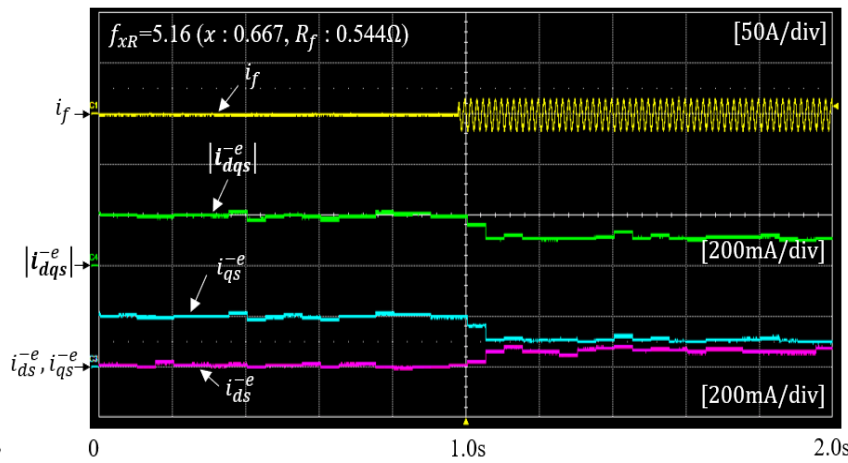

(d)

Figure 7. Experimental results of fault signals when the ITF occurs, (a) $f_{x R}=2.08\left(x: 0.8, R_{f}: 0.065 \Omega\right)$, (b) $f_{x R}=1.94\left(x: 0.667, R_{f}: 0.186 \Omega\right),(\mathbf{c}) f_{x R}=5.10\left(x: 0.8, R_{f}: 0.186 \Omega\right)$, and (d) $f_{x R}=5.16(x: 0.667$, $\left.R_{f}: 0.544 \Omega\right)$.

In Figure 8, the negative sequence currents in Figure 7 are presented in the $d-q$ coordinates. When $f_{x R}=2.08,1.94,5.10$, and 5.16 , the measured negative sequence deviations $\left|i_{d q s(I T F)}^{-e}\right|$ are $301,315,107$, and $113 \mathrm{~mA}$, respectively. Calculated negative sequence current deviations are 284, 308, 103, and $102 \mathrm{~mA}$ from Figure 2, and there are little differences between the calculated and measured values. Hence, unless the negative sequence current by the grid $i_{d q s, h}^{-e}$ is considered, it is very difficult to identify the fault signal from the total negative sequence current and diagnose the ITF, especially under light fault (high $f_{x R}$ ). For an accurate ITF diagnosis, a vector approach of the negative sequence current is required.

Figure 9 shows comparisons of the calculated and experimental results of Figure $9 \mathrm{a}$ the negative sequence currents and Figure $9 \mathrm{~b}$ copper losses at the ITF circuit with various $f_{x R}(x=0.8$ and 0.667$)$ conditions. The red squares and blue circles denote the experimental results in 5- and 3-turns fault, and the black line is calculation results using the induction motor ITF model (1). In Figure 9a, comparing the results of each experiment and calculation, it is shown that the negative sequence currents generated by the ITF are almost identical to each other at the similar $f_{x R}$, regardless of fault parameters $x$ and $R_{f}$. In Figure $9 \mathrm{~b}$, the copper loss was calculated by measuring the current $i_{a}$ flowing through the $a$-phase winding and the $i_{f}-i_{a}$ current flowing through the fault resistor. There are some errors between the calculated and experimental results. The measured $i_{f}-i_{a}$ is slightly larger than the model result. The copper loss is proportional to the square of the current; its error expands in Figure 9b. However, when it comes to comparing two experimental results, the copper losses are similar to fault conditions at the similar $f_{x R}$. 


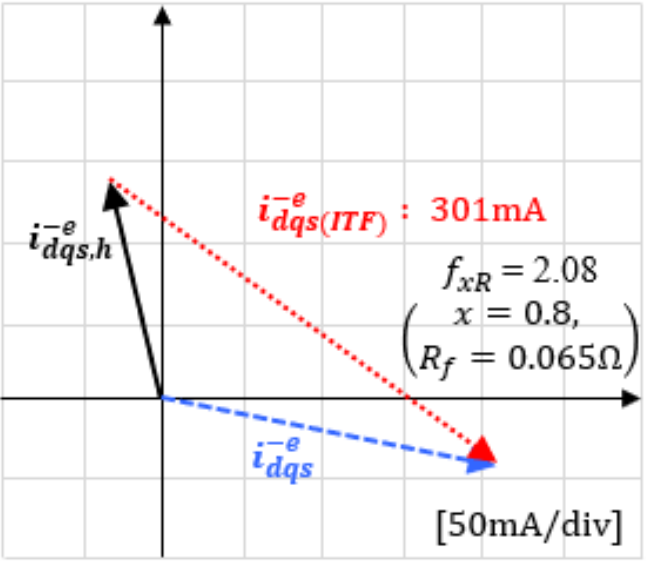

(a)

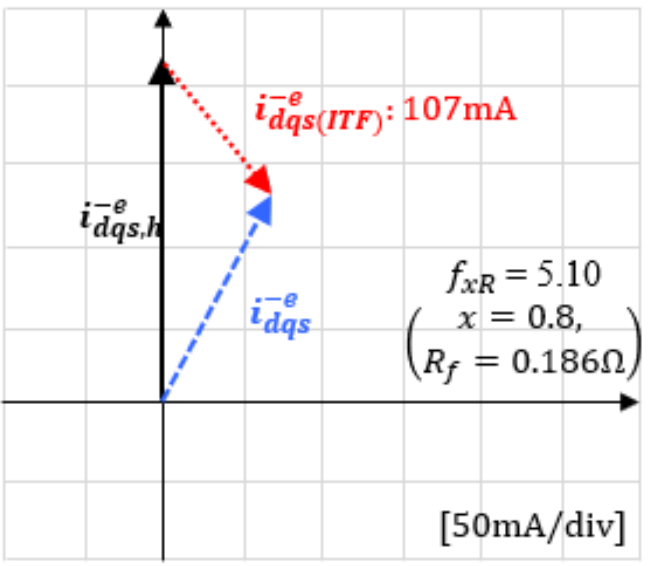

(c)

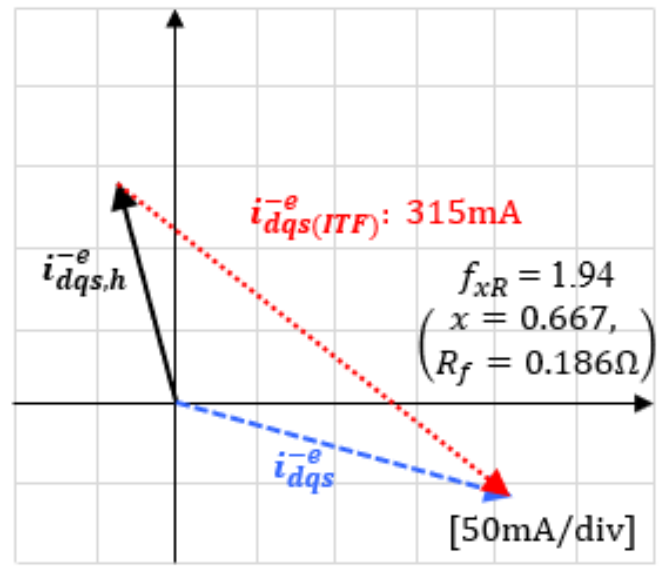

(b)

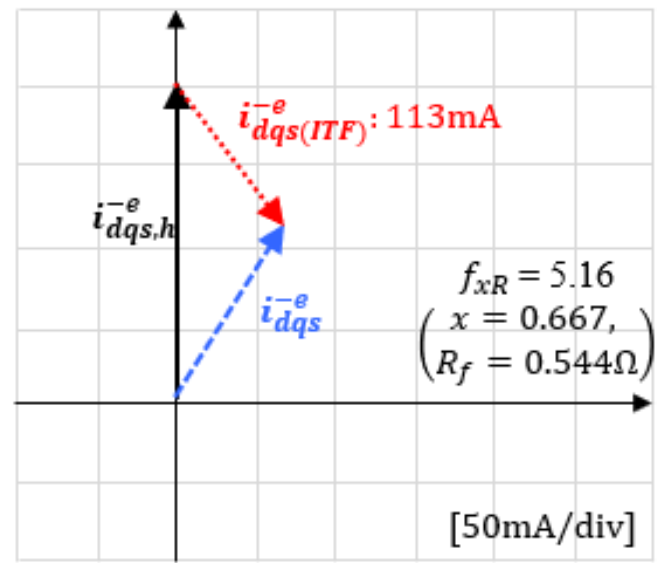

(d)

Figure 8. Negative sequence currents in the synchronous $\mathrm{d}-\mathrm{q}$ coordinates system, (a) $f_{x R}=2.08$ $\left(x: 0.8, R_{f}: 0.065 \Omega\right),(\mathbf{b}) f_{x R}=1.94\left(x: 0.667, R_{f}: 0.186 \Omega\right),(\mathbf{c}) f_{x R}=5.10\left(x: 0.8, R_{f}: 0.181 \Omega\right)$, and (d) $f_{x R}=5.16\left(x: 0.667, R_{f}: 0.544 \Omega\right)$.

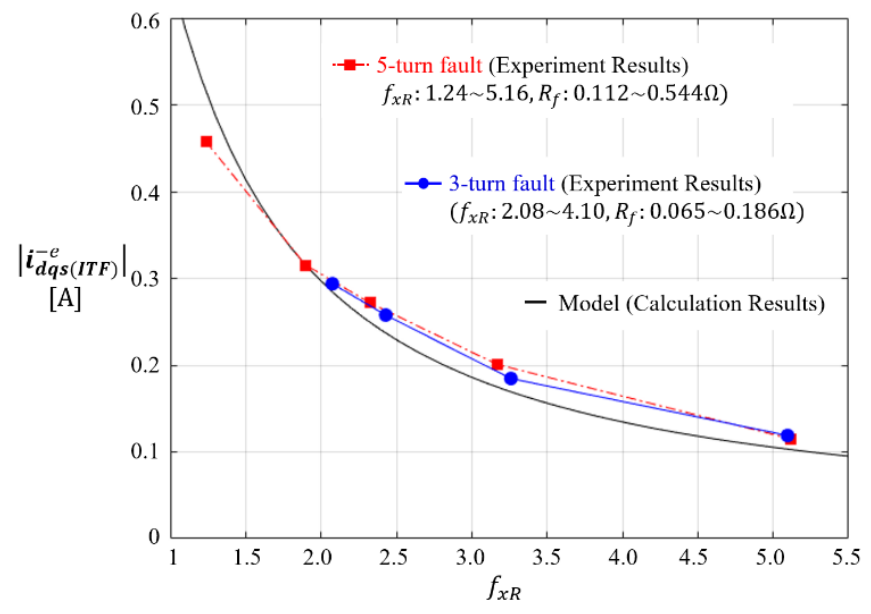

(a)

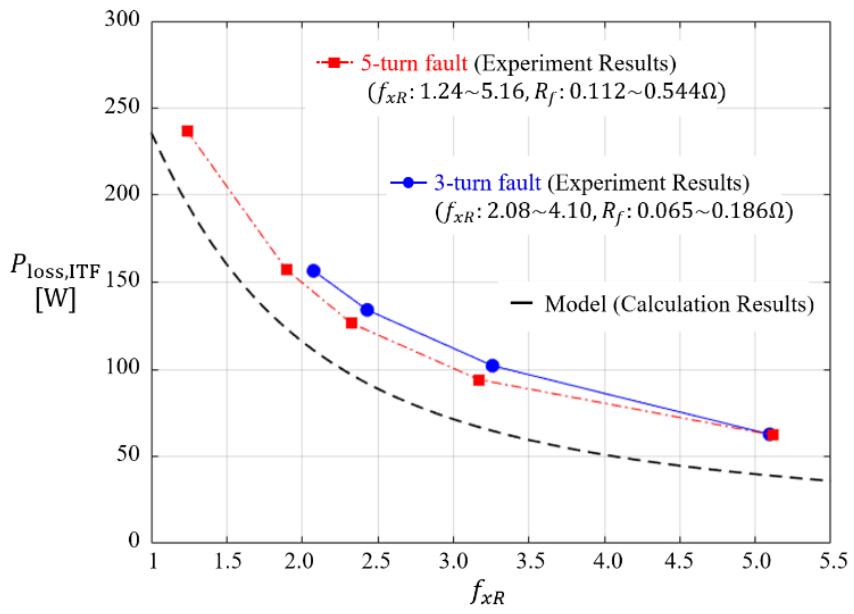

(b)

Figure 9. Calculated and experimental results of (a) the negative sequence current and (b) the copper loss generated in the ITF circuit vs. $f_{x R}$. 


\subsection{Inter-Turn Fault Diagnosis Method}

From Figure 3 and (6), it was presented that the negative sequence current $i_{d q s(I T F)}^{-e}$ and the additional copper loss $P_{I T F, \text { total }}$ by the ITF are determined by $f_{x R}$. To diagnose the ITF, the negative sequence current is utilized in the proposed diagnosis method, as shown in Figure 5. After fault diagnosis, if the motor has an ITF, $f_{x R}$ is estimated to obtain fault severity and additional power loss by the ITF $P_{I T F, \text { total }}$.

Figure 10 shows the experimental results when $f_{x R}$ are 1.28 (Figure 10a, $x=0.667$, $R_{f}=0.112 \Omega$ and 5.16 (Figure 10b, $x=0.667, R_{f}=0.544 \Omega$ ), respectively. The voltage and current sampling frequency is $5 \mathrm{kHz}$, and the diagnosis method is executed every $50 \mathrm{msec}$. Here, the number of faulted turns is 5-turns. With the proposed ITF diagnosis method, the healthy motor negative sequence currents $i_{d q s, h}^{-e}$ are calculated and subtracted from the measured negative sequence $i_{d q s}^{-e}$ in real time to obtain the ITF negative sequence current $\left(i_{d q s(I T F)}^{-e}=i_{d q s}^{-e}-i_{d q s, h}^{-e}\right)$. Without the ITF, $i_{d q s(I T F)}^{-e}$ is almost zero. After $1.0 \mathrm{~s}$, the external switch is turned on to create the ITF condition. The ITF circuit is formed by the fault resistor at the stator winding, and the fault current $i_{f}$ flows through the closed loop. The ITF negative sequence current $\left|i_{d q s(I T F)}^{-e}\right|$ increases rapidly as the three-phase balanced components of the motor becomes unbalanced, owing to the ITF, and it is regarded as an ITF if $\left|i_{d q s(I T F)}^{-e}\right|$ continuously exceeds the threshold current $(30 \mathrm{~mA})$, which is the maximum value of $I i_{d q s(I T F)}^{-e} I$ in the absence of ITFs. The $30 \mathrm{~mA}$ threshold current occurs when $f_{x R}>17.1$. In the case of one turn fault $(x=14 / 15), R_{f}$ is $0.07 \Omega$, and the fault current would be $11.9 \mathrm{~A}$, which is quite a light fault. In the experiment, the fault counter is accumulated to the limit at about $1.5 \mathrm{~s}$, and at that time, it is judged as the ITF. To estimate $f_{x R}$, the table $f_{x R}\left\{l i_{d q s(I T F)}^{-e} \mid\right\}$ from the ITF model is used. In Figure 10a,b, $\left|i_{d q s(I T F)}^{-e}\right|$ were $476 \mathrm{~mA}$ and $127 \mathrm{~mA}$, respectively, and $f_{x R}$ were estimated to be 1.32 and 5.0, respectively. The compared results show that the estimated and real $f_{x R}$ were almost similar to each other, but the fluctuation of the estimated $f_{x R}$ was greatest when $f_{x R}$ is 5.22 , as shown in Figure 10b. This is because the $f_{x R}$ vs. $\left|i_{d q s(I T F)}^{-e}\right|$ curve is declined with low slope when $f_{x R}$ is large, so it is sensitive at the light ITF. The proposed ITF diagnosis method was verified by performing the experiments, and it shows quite accurate ITF diagnosis and fault severity index $f_{x R}$ estimation.
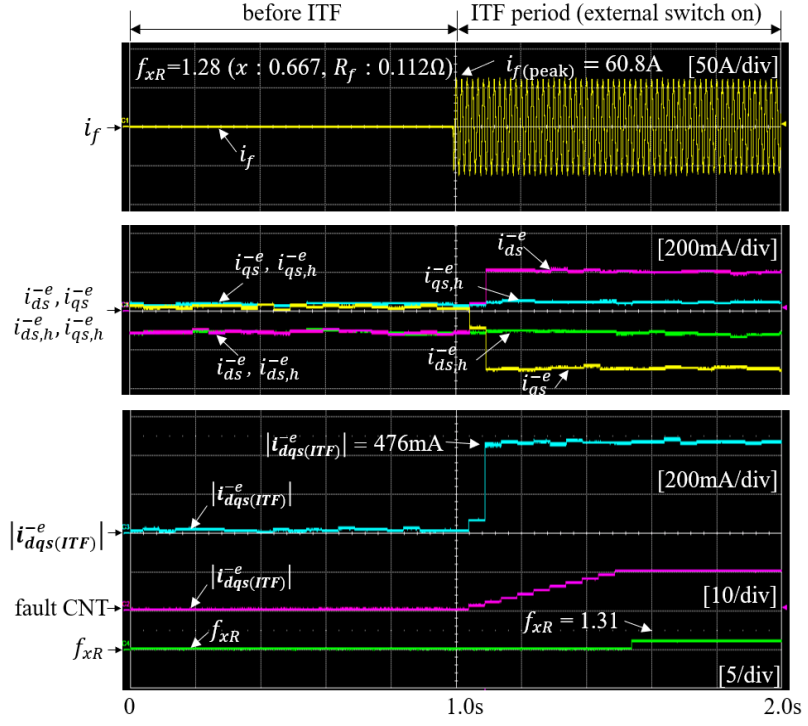

(a)
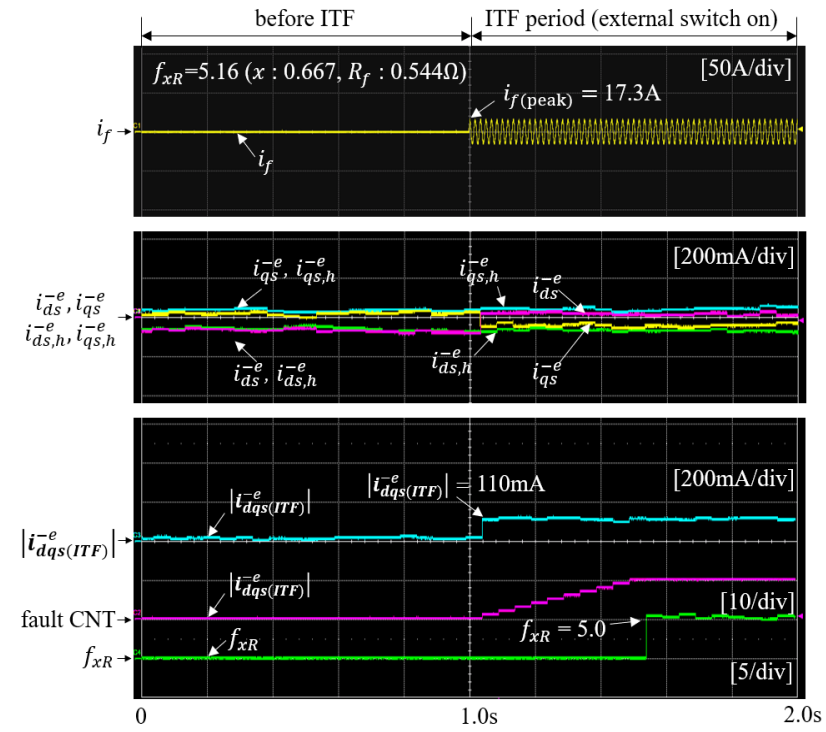

(b)

Figure 10. Experimental results of the proposed ITF diagnosis and $f_{x R}$ estimation method, (a) $f_{x R}=1.28$ $\left(x: 0.667, R_{f}: 0.112 \Omega\right)$, and $(\mathbf{b}) f_{x R}=5.16\left(x: 0.667, R_{f}: 0.544 \Omega\right)$. 
Figure 11 shows the calculation and experimental results of the negative sequence current in the synchronous $\mathrm{d}-\mathrm{q}$ coordinates system. Black, blue, and red solid lines denote the calculated results when $a-, b-$, and $c$-phase has an ITF $\left(f_{x R}: 1 \sim \infty\right)$, respectively. The point $\mathbf{F}$ shows the experimental result of $i_{d q s(I T F)}^{-e}$, which is from Figure 10a. A, B, and C are the points where the circle with diameter $\overline{\mathbf{O F}}$ and center $\mathbf{O}$ and $a-, b-$, and $c$-winding fault lines intersect, respectively. In the case of the experiment depicted in Figure 10a, it correctly diagnosed an ITF in the a-winding because $\mathbf{A}$ is the nearest point among $\mathbf{A}, \mathbf{B}$, and $\mathbf{C}$ from $\mathbf{F}$. Hence, it is possible to estimate where the ITF occurred by considering the phase of negative sequence current.

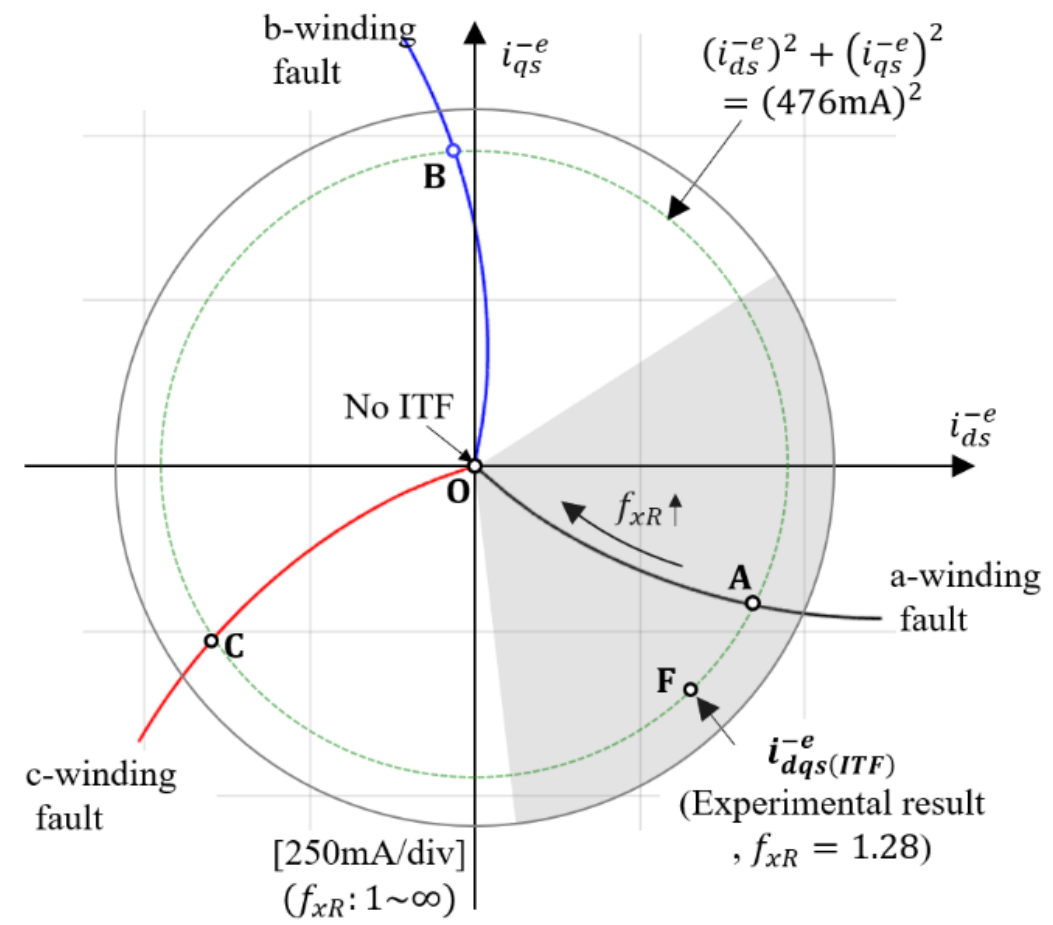

Figure 11. Calculation and experimental results of the negative sequence current with $a-, b-$, and $c$-phase ITF in the synchronous $\mathrm{d}-\mathrm{q}$ coordinates system.

\section{Conclusions}

In this study, an ITF diagnosis method was proposed based on the induction motor ITF model. The negative sequence current and copper loss due to the ITF are analyzed with the simplified circuit and equation. The relationship between the negative sequence current, copper loss, and the fault degree was derived with functions of the fault severity index $f_{x R}$. Furthermore, it was proven that the negative sequence current and copper loss are constant when $f_{x R}$ is constant throughout the experiments. The ITF diagnosis method was developed utilizing the table $f_{x R}\left\{\left|i_{d q s(I T F)}^{-e}\right|\right\}$ and it was validated experimentally in various fault conditions.

Author Contributions: Conceptualization, S.-H.I. and B.-G.G.; methodology, S.-H.I. and B.-G.G.; software, S.-H.I.; validation, S.-H.I. and B.-G.G.; formal analysis, S.-H.I. and B.-G.G.; investigation, S.-H.I. and B.-G.G.; resources, S.-H.I. and B.-G.G.; data curation, S.-H.I. and B.-G.G.; writing-original draft preparation, S.-H.I.; writing—review and editing, S.-H.I. and B.-G.G.; visualization, S.-H.I. and B.-G.G.; supervision, B.-G.G.; project administration, B.-G.G.; funding acquisition, B.-G.G. All authors have read and agreed to the published version of the manuscript.

Funding: This work was partly supported by the KEIT Technology Innovation Program (20011387, "Development of $50 \mathrm{~kW}$ vertical multistage smart fire pump system") funded By the Ministry of Trade, Industry \& Energy(MOTIE, Korea) and by the Basic Science Research Program through the National Research Foundation of Korea(NRF) funded by the Ministry of Education(No. 2020R1I1A3A04036842). 


\section{Institutional Review Board Statement: Not applicable.}

Informed Consent Statement: Not applicable.

Conflicts of Interest: The authors declare no conflict of interest.

\section{References}

1. Grubic, S.; Aller, J.M.; Lu, B.; Habetler, T.G. A survey on testing and monitoring methods for stator insulation systems of low-voltage induction machines focusing on turn insulation problems. IEEE Trans. Ind. Electron. 2008, 55, 4127-4136. [CrossRef]

2. Riera-Guasp, M.; Antonino-Daviu, J.A.; Capolino, G. Advances in electrical machine, power electronic, and drive condition monitoring and fault detection: State of the Art. IEEE Trans. Ind. Electron. 2015, 62, 1746-1759. [CrossRef]

3. Cygan, P.; Laghari, J.R. Models for insulation aging under electrical and thermal multistress. IEEE Trans. Electr. Insul. 1990, 25, 923-934. [CrossRef]

4. Bruning, A.M.; Campbell, F.J. Aging in wire insulation under multifactor stress. IEEE Trans. Electr. Insul. 1993, 28, 729-754. [CrossRef]

5. Saha, T.K.; Darveniza, M.; Yao, Z.T.; Hill, D.J.T.; Yeung, G. Investigating the effects of oxidation and thermal degradation on electrical and chemical properties of power transformers insulation. IEEE Trans. Power Deliv. 1999, 14, 1359-1367. [CrossRef]

6. Morin, R.; Bartnikas, R.; Ménard, P. A three-phase multi-stress accelerated electrical aging test facility for stator bars. IEEE Trans. Energy Convers. 2000, 15, 149-156. [CrossRef]

7. Siddique, A.; Yadava, G.S.; Singh, B. A review of stator fault monitoring techniques of induction motors. IEEE Trans. Energy Convers. 2005, 20, 106-114. [CrossRef]

8. Kavanagh, D.F.; Gyftakis, K.N.; McCulloch, M.D. Thermal degradation phenomena of polymer film on magnet wire for electromagnetic coils. IEEE Trans. Ind. Appl. 2021, 57, 458-467. [CrossRef]

9. Joksimovic, G.M.; Penman, J. The detection of inter-turn short circuits in the stator windings of operating motors. IEEE Trans. Ind. Electron. 2000, 47, 1078-1084. [CrossRef]

10. Cruz, S.M.A.; Cardoso, A.J.M. Diagnosis of stator inter-turn short circuits in DTC induction motor drives. IEEE Trans. Ind. Appl. 2004, 40, 1349-1360. [CrossRef]

11. Drif, M.; Cardoso, A.J.M. Stator fault diagnostics in squirrel cage three-phase induction motor drives using the instantaneous active and reactive power signature analyses. IEEE Trans. Ind. Inform. 2014, 10, 1348-1360. [CrossRef]

12. Cruz, S.M.A.; Cardoso, A.J.M. Stator winding fault diagnosis in three-phase synchronous and asynchronous motors, by the extended Park's vector approach. IEEE Trans. Ind. Appl. 2001, 37, 1227-1233. [CrossRef]

13. Cardoso, A.J.M.; Cruz, S.M.A.; Fonseca, D.S.B. Inter-turn stator winding fault diagnosis in three-phase induction motors, by Park's vector approach. IEEE Trans. Energy Convers. 1999, 14, 595-598. [CrossRef]

14. Luo, P.; Yang, Y.; Xu, J. Detection of inter-turn short-circuit fault in induction motors, by Park's vector difference approach. In Proceedings of the 2021 IEEE 4th Advanced Information Management, Communicates, Electronic and Automation Control Conference (IMCEC), Chongqing, China, 18-20 June 2021.

15. Husari, F.; Seshadrinath, J. Inter-turn fault diagnosis of induction motor fed by PCC-VSI using Park vector approach. In Proceedings of the 2020 IEEE International Conference on Power Electronics Drives and Energy Systems (PEDES), Jaipur, India, 16-19 December 2020; pp. 1-6.

16. Toliyat, H.A.; Lipo, T.A. Transient analysis of cage induction machines under stator, rotor bar and end ring faults. IEEE Trans. Energy Convers. 1995, 10, 241-247. [CrossRef]

17. Wu, Q.; Nandi, S. Fast single-turn sensitive stator interturn fault detection of induction machines based on positive- and negative-sequence third harmonic components of line currents. IEEE Trans. Ind. Appl. 2010, 46, 974-983.

18. Surya, G.N.; Khan, Z.J.; Ballal, M.S.; Suryawanshi, H.M. A simplified frequencyd-domain detection of stator turn fault in squirrel-cage induction motors using an observer coil technique. IEEE Trans. Ind. Electron. 2017, 64, 1495-1506. [CrossRef]

19. Irhoumah, M.; Pusca, R.; Lefevre, E.; Mercier, D.; Romary, R.; Demian, C. Information fusion with belief functions for detection of interturn short-circuit faults in electrical machines using external flux sensors. IEEE Trans. Ind. Electron. 2018, 65, $2642-2652$. [CrossRef]

20. Filho, P.C.M.L.; Baccarini, L.M.R.; Batista, F.B.; Araújo, A.C. Orbit analysis from a stray flux full spectrum for induction machine fault detection. IEEE Sens. 2016, 21, 16152-16161. [CrossRef]

21. Eftekhari, M.; Moallem, M.; Sadri, S.; Hsieh, M.F. Online detection of induction motor's stator winding short-circuit faults. IEEE Syst. J. 2014, 8, 1272-1282. [CrossRef]

22. Tallam, R.M.; Habetler, T.G.; Harley, R.G. Transient model for induction machines with stator winding turn faults. IEEE Trans. Ind. Appl. 2002, 38, 632-637. [CrossRef]

23. Tallam, R.M.; Habetler, T.G.; Harley, R.G. Stator winding turn-fault detection for closed-loop induction motor drives. IEEE Trans. Ind. Appl. 2003, 39, 720-724. [CrossRef]

24. Kumar, R.R.; Randazzo, V.; Cirrincione, G.; Cirrincione, M.; Pasero, E.; Tortella, A.; Andriollo, M. Induction machine stator fault tracking using the growing curvilinear component analysis. IEEE Access 2020, 9, 2201-2212. [CrossRef]

25. Kim, M.; Jung, J.H.; Ko, J.U.; Kong, H.B.; Lee, J.; Youn, B.D. Direct Connection-Based Convolutional Neural Network (DC-CNN) for Fault Diagnosis of Rotor Systems. IEEE Access 2020, 8, 172043-172056. [CrossRef] 
26. Maraaba, L.S.; Milhem, A.S.; Nemer, I.A.; Al-Duwaish, H.; Abido, M.A. Convolutional neural network-based inter-turn fault diagnosis in LSPMSMs. IEEE Access 2020, 8, 81960-81970. [CrossRef]

27. Im, S.-H.; Gu, B.-G. Study of induction motor inter-turn fault part I: Development of fault models with distorted flux representation. Energies 2022, 15, 894. [CrossRef]

28. Gu, B.-G. Study of IPMSMs interturn fault Part II: Online fault parameter estimation. IEEE Trans. Power Electron. 2016, 31, 7214-7223. [CrossRef]

29. Im, S.-H.; Gu, B.G. Interturn fault tolerant drive method by limiting copper loss of interior permanent magnet synchronous motor. IEEE Trans. Ind. Electron. 2020, 67, 7973-7981. [CrossRef] 